\title{
Solar Energy Healing Called Elle Ayat
}

\author{
Anna Koziol \\ Kaliningrad University, USA
}

\begin{abstract}
Ayat is a system of self-improvement of health and self-consciousness, which was proposed by Abdullayev Farkhat Muhamedovich more than 20 years ago and today, is used by many people all over the world. It helps thousands to regain health and live normal healthy and happy life.
\end{abstract}

Corresponding author: Anna Koziol, Kaliningrad University, USA. E-mail: annakoz02@gmail.com

Received: April 25,2020; Accepted: April 29,2020; Published: May 02,2020

Keywords: Solar energy, Healing, Physical problem

\section{About the method of Farkhat Ata}

We all know that it is very difficult to be happy when there is troubling physical problem. At the same time human mind, its inner consciousness and degree of its openness are the vital elements to being healthy. Ayat is a method that allows people to restore health and improve quality of life through the opening of own consciousness. Ayat is a selfhealing system, which works through combination of special techniques and principles pioneered by Abdullayev Farkhat Muhamedovich or simply Farkhat Ata. Farkhat ata has been worked actively since 1992, curing and helping people, sharing with people knowledge and his wondrous abilities. In doing so, Farkhat Ata created a method of self-help, which is available to anyone irrespective of race, nationality, wealth, religion or any other divisions that exists in today's world - a true gift for the whole humanity.

Over the course of his life, Abdullayev Farkhat Muhamedovich took part in many international forums, congresses, conferences dedicated to finding new ways and techniques for restoring human health. Farkhat Ata was recognized with many honors and diploma awards. But for him those conferences and trips were simply the opportunities to meet and help as many people as possible. People who were lucky to meet him, say that Farkhat Ata was radiating light and warmth and kindness, waking people up and giving them true hope and wiliness to live.

For Farkhat ata it has never been important the assignment of ranks and titles. Every person is important. A healthy person with open mind - this is how he saw us all. A person that is thinking positively, speaking positively, doing positive things, tuned to the individual work on the rehabilitation and opening of consciousness. MAN in the truest sense of the word. And for that Farkhat Ata has left us Elle Ayat method, so anyone could find the way to be healthy and show the way to others.

Today, tens of thousands of followers and students are the testament and the result of hard work of Abdullayev Farkhat Muhamedovich. 
Citation: Anna Koziol (2020) Solar energy healing called Elle Ayat. Journal of Physical Medicine Rehabilitation Studies \& Reports. SRC/JPMRS/105. DOI: doi.org/10.47363/JPMRS/2020(2)104

\section{The Ayat techniques}

The healing technique of Farkhat ata is simple and accessible to anyone seeking health. There are four rules of Ayat that can achieve good results in the restoration of health and the development of consciousness. Any person, regardless of their social and financial position can get better by practicing four simple techniques.

\section{First is the Formula of Life:}

Elle Nina Ana Sozdatel Farkhat Ata

Elle Ayat 37406810

Elle Lezzet Selennoi

Elle Uyghur Ayat Elle

The formula of Life has been created by Farkhat ata through the consciousness of his students. Each word has its own meaning and together they create a very unique frequency allowing anyone saying it to tune to a source of the healing energy stream, related to solar energy. The true power of the formula of Life is not yet understood, but its positive effects are admired amongst Ayat practicing community. When directly translated, the formula of Life sounds like this:

Elle Nina ana Creator Farkhat Ata

Elle Ayat 37406810

Elle LEZZET Universe

Elle Uyghur Ayat Elle

\section{Second}

Drinking Etkin tea, this is considered to be an energy replenishing, as well as having healing properties, drink. It is prepared by brewing a regular black tea, adding some milk and a pinch of salt, and pronouncing the formula of Life. It is important when preparing Etkin tea, to try to get rid of any thoughts and say the formula of Life, focusing all your attention on the formula.

\section{Third}

Working with the sun by looking at it, after pronouncing the formula of Life and then listening to your own inner feelings. At first, it should be done very carefully, possibly at sunrise or sunset, or through greenery, do not harm your eyes. In any case, it should not be done for more than 3 minutes at a time, but unlimited number of times during a day, just as you feel like. It even can be done on a cloudy day, just by looking in sun's direction. Sun and its energy is always out there for us, whether we see it or not. The formula of Life allows us to harness solar light and its energy in a very special way, healing our bodies and minds.

It is a very powerful way of connecting to and understanding your true self. It helps to obtain calm and compose state of mind that aids in healing, finding right ways to achieve desired by asking and hearing or realizing the answers. Farkhat Ata used to say, that if you have a question, than you have an answer too. You just have learnt to hear it from within.

The forth is to try to create a positive the positive creative style of life: dancing, singing, doing music, arts, creating and maintaining friendship etc. It is widely recognized that by doing something new, possibly long desired activity, like learning to dance or sing and in the process, overcoming fears and constrains, can bring positive change in people's lives. It changes focus and let us to discover new potentials, lying hidden within each of us.

All aspects and techniques of Elle Ayat method coexist in harmony, together creating a helping hand for anyone seeking to regain health and generally to change life for the better. Our bodies and our minds work in synergy to achieve a happy state.

The media of different countries pays attention to the Ayat recovery system, trying to understand the essence of the proposed method. Over the years there were many articles in "Morning of the capital" Astana, with headlines:

\section{"The phenomenon of Ayat - a mystery for scientists" "Formula of life" \\ "Health - is perfection"}

"Life without drugs - this is happiness" and many others newspapers and magazines.

In July 2005, Moskovsky Komsomoletsts published an article by a correspondent Yulia Kalinina which was called "Connection to happiness".

Journal Bulletin of Traditional Medicine published an article "Welcome to all the people of Earth"

Latvian business magazine published an essay "Ayat - life without diseases and drugs'

There also were many attempts at analyzing the method of Abdullayev Farkhat Mukhamedovich. It was searched by the Federal Agency for improvement of health and social development and by the Federal Scientific clinical-experimental center of traditional diagnostic methods and treatment De- 
Research by the faculty of biology, Lomonosov Moscow State University, emphasized that the most important in the method Elle Ayat of Farkhat Ata is its ability to help anyone to become a healthy person, living normal happy life.

Patients of different age, different social groups who received healing through the method also tend to change their understanding of life and their place in the world. All of them have good results, related to the restoration of their health irrespective of social or material status, age or nationality, with or without of any religious beliefs.

Driven by desire to help people, many of former patients subsequently become disciples of Farkhat Ata, sharing their feelings with newcomers, helping them to understand and accept this recovery system.

To confirm the efficiency and safety of human exposure to the system of self-improvement and development of consciousness by Abdullayev Farkhat Muhamedovich, Federal Scientific Clinical and Experimental Center of traditional methods of diagnosis and treatment carried out a number of studies.

A number of scientific and medical researches of the system Ayat of the method of Abdullayev Farkhat Mukhamedovich have been conducted. There exists a report of scientific evidences, relating to the change of the phase state of water under the influence of "Etken tea" with formula of Life of Farkhat Ata. It contains an opinion on bioenergy and biological properties of Etken tea before and after exposure to the formula of Life Farkhat Ata. The experiment found the exposure to formula of Life changes the functional state of tea. These is studies have been conducted on the biological faculty of Moscow State University.

There is statistical evidence, based on reviews of former patients, who get better by using method Elle Ayat method. Results achieved by people, practicing the Ayat system often stunned doctors who simply saw the results that were not possible to achieve in academic medicine.

The method of Ayat provides the opportunity for everyone to become healthy and happy which is the most important.
Copyright: (C2020 Anna Koziol. This is an open-access article distributed under the terms of the Creative Commons Attribution License, which permits unrestricted use, distribution, and reproduction in any medium, provided the original author and source are credited. 